\title{
Interplay between the Genetics of Personality Traits, severe Psychiatric Disorders, and COVID-19 Host Genetics in the Susceptibility to SARS-COV-2 Infection - ADDENDUM
}

Urs Heilbronner, Fabian Streit, Thomas Vogl, Fanny Senner, Sabrina K. Schaupp, Daniela Reich-Erkelenz, Sergi Papiol, Mojtaba Oraki Kohshour, Farahnaz Klöhn-Saghatolislam, Janos L. Kalman, Maria Heilbronner, Katrin Gade, Ashley L. Comes, Monika Budde, Till F. M. Andlauer, Heike Anderson-Schmidt, Kristina Adorjan, Til Stürmer, Adrian Loerbroks, Manfred Amelang, Eric Poisel, Jerome Foo, Stefanie Heilmann-Heimbach, Andreas J. Forstner, Franziska Degenhardt, Jörg Zimmermann, Jens Wiltfang, Martin von Hagen, Carsten Spitzer, Max Schmauss, Eva Reininghaus, Jens Reimer, Carsten Konrad, Georg Juckel, Fabian U. Lang, Markus Jäger, Christian Figge, Andreas J. Fallgatter, Detlef E. Dietrich, Udo Dannlowski, Bernhardt T. Baune, Volker Arolt, Ion-George Anghelescu, Markus M. Nöthen, Stephanie H. Witt, Ole A. Andreassen, Chi-Hua Chen, Peter Falkai, Marcella Rietschel, Thomas G. Schulze and Eva C. Schulte

\section{Copyright and usage}

(C) The Author(s), 2021. Published by Cambridge University Press on behalf of the Royal College of Psychiatrists. This is an Open Access article, distributed under the terms of the creative Commons Attribution licence (https://creativecommons.org/licenses/by/4.0/), which permits unrestricted re-use, distribution, and reproduction in any medium, provided the original work is properly cited.

https://doi.org/10.1192/bjo.2021.1030, Published online by the Royal College of Psychiatrists, 7th October 2021.

An affiliation was missed for Thomas G. Schulze. The missed affiliation was for the Department of Psychiatry and Behavioral Sciences, SUNY Upstate Medical University, Syracuse, NY, USA. The Publisher apologises for this omission.

Urs Heilbronner; Fabian Streit; Thomas Vogl; Fanny Senner; Sabrina K. Schaupp Daniela Reich-Erkelenz; Sergi Papiol; Mojtaba Oraki Kohshour; Farahnaz KlöhnSaghatolislam; Janos L. Kalman; Maria Heilbronner; Katrin Gade; Ashley L. Comes; Monika Budde; Till F. M. Andlauer; Heike Anderson-Schmidt;
Kristina Adorjan; Til Stürmer; Adrian Loerbroks; Manfred Amelang; Eric Poisel; Jerome Foo; Stefanie Heilmann-Heimbach; Andreas J. Forstner;

Franziska Degenhardt; Jörg Zimmermann; Jens Wiltfang; Martin von Hagen; Carsten Spitzer; Max Schmauss; Eva Reininghaus; Jens Reimer; Carsten Konrad; Georg Juckel; Fabian U. Lang; Markus Jäger; Christian Figge; Andreas J. Fallgatter; Detlef E. Dietrich; Udo Dannlowski; Bernhardt T. Baune; Volker Arolt; Ion-George Anghelescu; Markus M. Nöthen; Stephanie H. Witt; Ole A. Andreassen; Chi-Hua Chen; Peter Falkai; Marcella Rietschel; Thomas G. Schulze; Eva C. Schulte (1)

\section{Reference}

Heilbronner, U., Streit, F., Vogl, T., Senner, F., Schaupp, S., Reich-Erkelenz, D., . Schulte, E. (2021). Interplay between the genetics of personality traits, severe psychiatric disorders and COVID-19 host genetics in the susceptibility to SARS-CoV-2 infection. BJPsych Open, 7(6), E188. doi:10.1192/bjo.2021.1030

OPEN

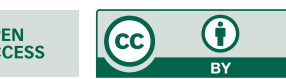

